\title{
COULD A MAN BE AFFECTED WITH CARCINOMA OF CERVIX? - THE FIRST CASE OF CERVICAL CARCINOMA IN TRANS-SEXUAL PERSON (FTM) - CASE REPORT
}

\author{
Daniel Driák ${ }^{1}$, Michal S̆amudovsk $\tilde{y}^{2}$ \\ Charles University in Prague, $1^{\text {st }}$ Faculty of Medicine, University Hospital Na Bulovce, Prague, Czech Republic: Gynaeco- \\ logical-obstetritian Department ${ }^{1}$, Department of Plastic Surgery ${ }^{2}$
}

Summary: The article presents an unique case of trans-sexual person (FtM) with histological finding of pre-invasive cervical carcinoma after performed hysterectomy.

Key words: Trans-sexualism; Cervical cancerogenesis; Papillomaviruses

\section{Introduction}

Trans-sexuality is a problem of gender identity. Modern surgical treatment enables affected individuals to be satisfied with changed genital and conduce relatively comfortable life. In anamnesis of such „a man“ may remain typical female diseases, resp. diseases bound to specific female organs (e.g. uterus, vagina, cervix).

\section{Trans-sexualism}

Trans-sexualism means completely antipodal sexual identity. Trans-sexual syndrome was firstly described by Harry Benjamin in 1953 (1,2). Harry Benjamin International Gender Dysphoria Association (HBIGDA), society establishing the protocol of diagnostic and therapy of transsexualism was founded in 1978 (6).

Sexual identity develops in early childhood through to adulthood in a complex process of sexual identification. As proven by experiments with hidden cameras parental behaviour differs according to the sex of the child during the first days of life. The differentiation is perceived by the newborn. Later the child distinguishes the difference between external genitals. The most crucial are the first 3 years of living.

Trans-sexual woman (FtM - Female-to-Male) is genetically, hormonally, and morphologically a woman, reared like a girl, but wants to look and act as a real man. Transsexual man ( $\mathrm{MtF}$ - Male-to-Female) is chromosomally, hormonally, and anatomically a man, brought up like a boy, although „he“ desires to be a complete woman. Trans-sexuals have the feeling of having been born with the wrong sex. Converse education as well as remaining in „contrary body“ brings them dysfory, stress, and psychical torment (12).

Besides genetic, behaviouristic, and psychogenic hypotheses that has been the subject of debate for many years, now the neurobiological disorder in the developing brain during gravidity seems to be scientifically well-founded. The gender identity develops as a result of an interaction between the developing brain and sex hormones. The essential cause lies in wrong advancement of sexual centres in hypothalamus, resp. in weak influence of sexual hormones on the sexual centres and cortex in an early stage of pregnancy. The mass of the central subdivision of the bed nucleus of the stria terminalis, a brain area that is essential for sexual behaviour, is larger in men than in women (14). The number of somatostatin neurons in base of nucleus of stria terminalis in limbic system in FtM-trans-sexual is equal to the male brain (approximately two times higher than in women), and the same one in MtF-trans-sexual resembles the female brain (8).

The frequency listed in textbooks is for MtF 1:20 000 -30 000 adult men and for FtM 1:50 000-100 000 adult women (6). Now, it seems that the frequency is much higher, e.g. 1:300-500 deliveries, resp. for MtF 1:2500. Transgenderism is an escalated trans-sexuality.

After determination of diagnosis the psychotherapy and long-term substitution therapy with high doses of hormones appropriate to the target sex is started. The operative change of genital is the ultimate method how instalate accordance between sexual centres in hypothalamus and human body. Surgical converse of gender in trans-sexuals basically means elimination of sexual glands and constitution of the oppo- 
site genital. The operation is complicated and consists of several steps logically following one another and changing more and more the appearance of genitalia.

The complete change of one gender to the opposite can last up to 2-3 years. Birth into „the new body“ and finding the new identity is a long-term process The efficacy of operative therapy is very high ( $97 \%$ ), although the new genitalia doesn't necessarily function $100 \%$ of the time.

\section{Cervical cancerogenesis}

Cervical cancer is still the second most common cancer in women worldwide and the most common gynaecological malignancy in the reproductive age. According to EU statistical studies, incidence of invasive cervical cancer in the Czech republic in 1995 was 21,6 with mortality 7,2, whereas the average incidence in EU member countries was 10,2 with mortality approximately 3 (9). In 1999 group of eminent Czech experts formulated the full-area, two-phase screening program for the detection of precancerosis of cervix (9).

The most common histopathological type is squamous cell carcinoma (90\%), the second one is adenocarcinoma (10\%), other types are extremely rare $(4,10)$.

Several factors are associated with an increased risk for this type of carcinoma. Previously, the high risk group of women was identified and risk factors considered: low socioeconomic status, risk sexual behaviour (high number of sexual partners, low age at first sexual intercourse, at first childbearing or in first marriage, risk sexual partner), multiparity, smoking, history of STD (syphilis, gonorrhea, herpes simplex virus - type 2, Chlamydia trachomatis), use of oral contraception, dietary factors (lack of vitamins A, C, folic acid) or any combination. Some of them have still to be re-evaluated - e.g. influence of COCs is indirect, associated with higher sexual activity, regular cytological surveillance, and blocked clearance of HPV (4). Others have been affirmed - e.g. cigarette smoking is associated with the increased risk (by 42-46 \%) for cervical carcinoma even after adjustment for age and number of sexual partners (11).

\section{Case report}

On February 5, 2003, the pacient X.Y., born March 23, 1965 , reccomended from a regional hospital was admitted into our clinic for surgical treatment of trans-sexualism.

\section{Anamnesis}

The patient was adopted by elder step-parents. Underwent appendectomy in 1979. Menarche at the age of 14, the cycle was regular $28 / 5$. Spontaneous delivery at the age of 25 , the baby consigned to the step-grandmother. Because of mother's despotism the crucial devious sexual self-identification was solved late, unfortunately. Not until 1999. was the patient treated hormonally for trans-sexualism FtM; firstly oral hormonal therapy, now parenteral injection of
Sustanon 250 ( $1 \mathrm{ml}$ of oil solution composited of testosteroni propionas $30 \mathrm{mg}$, testosteroni phenylpropionas $60 \mathrm{mg}$, testosteroni isocaproas $60 \mathrm{mg}$, testosteroni decanoas 100 $\mathrm{mg}$ ) each 3 weeks i.m.

\section{Gynaecological examination}

Crinis rather female, hypertrichosis of arms and legs, pubescence round the areolae mammae is male.

External genitalia: clitoris peniformis (length approximately $3 \mathrm{~cm}$ ). The breasts are ptotic, axillae free of resistance. There are many signs of scars after vulnera scissa (made by knife) on the breast as well as on the upper limbs and abdomen.

In speculas: cervix cylindrical with a quiescent transformation zone, the border of epitheliums is shifted into the cervical canal, cytological smears taken at regional hospital with negative outcomes.

Palpation: uterus AVF, normal size, adnexa without any resistence, ovarium bilaterally atrofic.

\section{Operation}

On the $6^{\text {th }}$ of February, the patient was operated on in department of plastic surgery with the assistance of a gynaecologist. Performed operation: Hysterectomy abdominalis, adnexectomy bilateralis, mastectomy subcutaneous with periareolar modelation bilateralis.

Postoperatively: The first 3 postoperative days subfebriles, therapy - infusions, analgetics, Unasyn (sultamicilin) $375 \mathrm{mg}$ each 12 hours orally, than afebrile, without any complication, passage renewed, the patient was demitted on the 4th day after operation. Extraction of sutures in the outpatient's department after 2 weeks.

\section{Histological findings}

Right and left breast - differentiated structures of lactic gland.

Cervix - in the region of transformation zone are localized deposits of squamous carcinoma in situ. The signs of invasion are not present.

Uterus - corporal endometrium atrofic, myometrium without any pathological changes.

Adnexa - without any pathological changes.

Summary - squamous carcinoma in situ of cervix, no invasion is present.

\section{Follow-up}

Gynaecological examination performed 4 weeks after operation, the vaginal stump completely healed, qiescent, smooth, elevated into small pelvis, without any palpable infiltrate. Normal postoperative findings.

Oncological consilium recommends only common dispensary, regular cytological smears from the vaginal stump, however, to let the vaginal stump open when the further operative adjustment of external genitalia will be performed. The open stump should assure the access to the epithelium and allow further oncological follow-up. 


\section{Discussion}

It is suggested that promotor or iniciator of the majority of cervical pre-malignant or malignant laesions is transmitted by the sexual intercourse. Thus, cervical cancer fullfills the criteria for STD (7). Non-sexual transmission can't be completely excluded. Infection can be transmitted by non lege artis performed routine gynaecological examination, contaminated under-wear, contact with microtrauma in swimming pool or sauna, or contaminated fingers in children (5).

At the current level of knowledge, the causal role of persistent HPV infection (type 16 and 18) in the development of cervical cancer has been proved beyond reasonable doubt. Intragenomic incorporation of HPV DNA is a necessary, non-sufficient cause of cervical cancer. HPV enters immature metaplastic basal stem cells that are activelly dividing and infection spreads and persists. HPV DNA is incorporated into the invaded cell DNA, included two mains transforming genes on transcriptional regions E6 and E7. Later, viral oncoproteins pE6 (150 aminoacids) and pE7 (98 aminoacids) are synthesized, and Ha-Ras proto-oncogene activated. Oncoproteins form the complex with antioncogene $\mathrm{p} 53$ and $\mathrm{pRB}$ protein, thus the tumor suppressors are inactivated and the process of tumorigenesis is iniciated $(3,5)$. It is suggested that the developing cervix (at the age of peri-menarche) or the healing cervix (as a consequence of delivery, cervical trauma or STD infection) are high risk situations for an HPV infection which can reach the basal layer and cause a persistent infection (3). On the other hand, pregnancy per se does not seem to adversely affect the survival of women with invasive cervical cancer (13). Additional factors combined with HPV (rather endogenous than of an environmental nature) may give sufficient cause. Carcinoma of cervix is theoretically a preventable disease. Prevention of exposure to high risk HPV types by vaccination may prove to be the most efficient intervention for cervical cancer (3).

In our clinic since 1999, 150 trans-sexual women FtM underwent operations. According to our knowledge, this is the first case of cervical cancer, fortunately operated on in the pre-invasive stage, that was observed in a trans-sexual person undergoing an operation for a sex-change. The patient has been hysterectomized and hysterectomy is an adequate and sufficient therapy (in women desiring of children is adequate operation conisation behind the border of unaffected tissue)

Despite of the normal outcomes of cytology, the carcinoma in situ was affirmed histologically.

Modern surgical treatment enables trans-sexuals to undergo a genital conversion and conduce a relatively satisfied life, however, diseases related to their original gender may occur. Involved physicians should remain alert for the occurrence of diseases related to the original genital.
The failure in pre-operative management might have been in incorrect evaluation of cytology, resp. in smear of non-representative sample. Preventing such a case of occassionally diagnosed carcinoma in future, we can assure ourselves that expert colposcopical examination and cytological smears in all patients before a planned operation for sex-change (i.e. hysterectomy et adnexectomy).

\section{Conclusion}

In the article authors describe the unique case of pre-invasive cervical cancer in trans-sexual FtM distinguished histologically after hysterectomy. Preventing such a case of „ex-post“ diagnosed carcinoma, involved physicians should provide colposcopical examination and cytological smears in all patients before a planned hysterectomy.

The condensed version of the paper in form of Letter to the Editor has been accepted for publishing in the European Journal of Cancer as an original source article.

\section{References}

1. Benjamin H. Transvestitism and transsexualism. J Sexuol 1953;7:12.

2. Benjamin H. Transvestitism and transsexualism as psycho-somatic and somatopsychic syndromes. Amer J Psychother 1954;8:219-30.

3. Bosch FX, Lorincz A, Muňoz N, Meijer CJLM, Shah KV. The causal relation between human papillomavirus and cervical cancer. J Clin Pathol 2002;55:244-65.

4. Citterbart K, Čech E, Donát J et al. Gynekologie. 1st ed, Prague: Galén, 2001:278.

5. Freitag P. Papillomaviry. Prague: Triton, 1998:88.

6. Jarolim L. Operation to the gender change of transsexuals. Rozhl Chir 1998;7:487-92.

7. Koleta F. Infekce a zánět v gynekologii a porodnictví. Prague: Grada Publishing, 1995:160

8. Kruijver FPM, Zhou J-N, Pool ChW, Hofman MA. Male-to-female transsexuals have female neuron numbers in a limbic nucleus. J Clin Endocrinol Metab 2000;85:2034-41.

9. Rob L, Rokyta Z, Ondruš J et al. Screeningový program - cervikální prekancerózy a rakovina. Server Levret, www.levret.cz.

10. Sobin LH, Wittekind Ch. TNM classification of malignant tumours. Prague: Institute of Health Information and Statistics of the Czech Republic, 2000:190.

11. Sood AK. Cigarette smoking and cervical cancer: meta-analysis and critical review of recent studies. Am J Prev Med 1991;7:208-13.

12. Švecová B, Weiss P. To some differences between trans-sexuals male-to-female and female-to-male. Čes Slov Psych 2001;97:13-9.

13. Zemlickis D, Lishner M, Degendorfer P, Panzarella T, Sutcliffe SB, Koren G Maternal and fetal outcome after invasive cervical cancer in pregnancy. J Clin Oncol 1991;9:1956-61

14. Zhou J-N, Hofman MA, Gooren LJ, Swaab DF. A sex difference in the human brain and its relation to transsexuality. Nature 1995;378:68-70.

Submitted August 2004.

Accepted October 2004.

MUDr. Daniel Driák,

Charles University in Prague,

$1^{\text {st }}$ Faculty of Medicine,

University Hospital Na Bulovce,

Gynaecological-obstetritian Department,

Budínova 2, 18081 Prague,

Czech Republic.

e-mail:driak@seznam.cz 